\title{
$\mathrm{DEA}$ 기법을 이용한 낙지통발어업의 어획능력 측정 \\ 김도훈 · 안희춘' \\ 국립수산과학원 정책홍보팀, ${ }^{1}$ 국립수산과학원 수산공학팀
}

\section{Fishing capacity assessment of the octopus coastal trap fishery using data envelopment analysis(DEA)}

\author{
Do-Hoon KIM*, Heui-Chun AN ${ }^{1}$, Kyoung-Hoon LEE $^{1}$ and Jin-Wook HwANG \\ Fisheries Economics \& Public Affairs Team, National Fisheries Research \& \\ Development Institute, Busan 619 -902, Korea \\ ${ }^{1}$ Fisheries Engineering Team, NFRDI, Busan 619-902, Korea
}

Estimating fishing capacity is one of current hot issues in the international fisheries. It is because that increased fishing capacity has caused not only fish stocks to be reduced, but also additional fishing costs to be incurred without additional incomes, which resulted in decrease of economically viability of fisheries. In order to solve this problem, FAO adopted 'the International Plan of Action for the Management of Fishing Capacity' in 1999 and recommended that member countries to measure fishing capacity and to implement the domestic action plan to reduce excess fishing capacity. This study is aimed at assessing fishing capacity of the octopus coastal trap fishery(OCTF) using data envelopment analysis(DEA) which is a method recommended by FAO. The DEA results on 10 individual OCTF vessels showed that the capacity utilization(CU) was a 0.93 on average, indicating some differences in CU among vessels(0.79-1.0). In addition, results of the sensitivity analysis revealed that under the current level of catch, the gross tonnage, horse power, days fished, and traps per trip could be reduced by $35 \%, 33 \%, 16 \%$, and $18 \%$ on average, respectively

Key words : Fishing capacity, Data envelopment analysis(DEA), Trap fishery, Octopus

서 론 최근 국내외적인 어업자원의 감소경향이 심
각해지면서 어획능력 감소에 대한 국제적 관심 이 증대하고 있다. 이는 적정 수준 이상으로 어

\footnotetext{
*Corresponding author: kimdh@nfrdi.re.kr, Tel: 82-51-720-2081, Fax: 82-51-720-2089
} 
획할 수 있는 유휴 어획능력(fishing capacity)이 어업에 존재할 경우 이에 대한 완전한 통제 및 관리가 이루어지지 않게 되면 결국 어업자원에 대한 남획을 초래하여 더욱 심각한 자원량 감소 를 야기할 수 있기 때문이다. 또한 적정 수준 이 상으로 어획능력이 증가하게 되면 그 만큼의 어 업비용이 발생하게 되는데, 유휴 어획능력에 대 한 추가적인 어업수입 없는 초과비용 발생은 결 국 어업경영에 부정적인 영향을 끼치게 된다.

이에 따라 세계식량농업기구(FAO)에서는 1995년 '책임 있는 수산업 규범(Code of conduct for responsible fisheries)' 채택 시 가장 핵심적인 내용 중의 하나로 과잉어획능력(overcapacity) 감 소를 제안하였다. 그리고 이 규범의 실질적 이행 을 위해 1999년 FAO 제23차 수산위원회에서 '어 획능력 관리를 위한 국제적 행동계획(International plan of action for the management of fishing capacity)' 을 수립하여 각국으로 하여금 우선적 으로 어업별 어획능력을 측정하고, 과잉어획능 력 감축을 위한 관리방안 마련을 촉구하였다 (FAO, 1999).

어획능력은 흔히 '어느 한 척의 어선 혹은 어 선단이 어획할 수 있는 능력' 으로 정의될 수 있 는데, 선행연구에서 어획능력은 크게 생산적인 (production) 개념과 경제적인(economic) 개념으 로 정의되고 있다(Zheng and Zhou, 2005; Pascoe et al., 2004; Kirkley et al., 2001; Nelson, 1989; Morrison, 1985a and 1985b). 생산적인 개념에서 의 어획능력은 생산 최대화에 근거하여 주어진 시장여건, 어업자원상태, 기술적 상황 하에서 조 업활동에 아무런 제약조건이 없을 경우 일정 기 간동안 어선(혹은 선단)이 산출할 수 있는 최대 생산량을 의미한다. 이에 반해, 경제적인 개념의 어획능력은 비용 최소화에 근거하여 주어진 시 장여건, 어업자원상태, 기술적 상황 하에서 조업 활동에 아무런 제약조건이 없을 경우 일정 기간 동안 어선(혹은 선단)이 산출할 수 있는 가장 경 제적인 생산량 수준을 의미한다.
경제적인 개념의 어획능력을 측정하기 위해 서는 조업활동과 관련된 비용 등의 경제적인 자 료가 구비되어야 하는데, 이러한 자료를 수집하 는 것은 현실적으로 거의 불가능하다. 또한 일반 적으로 다양한 투입요소를 사용하여 다양한 종 류의 어종을 어획하는 어업의 경우 경제적인 개 념의 어획능력을 측정하는데 현실적인 어려움 이 많다. 이에 따라 FAO 전문가그룹회의에서는 어획능력을 생산적인 개념으로 정의하고, 이에 근거하여 어업별 어획능력을 측정하도록 제안 하였다(FAO, 2000). 즉, Johansen(1968)의 정의와 같이 주어진 시장여건, 어업자원상태, 기술적 상 황 하에서 조업활동에 아무런 제약조건이 없을 경우 일정 기간동안 어선(혹은 선단)이 산출할 수 있는 잠재적인 최대 생산량을 구하고, 이를 실제 생산량 수준과 비교하여 어획능력의 과잉 정도를 측정하도록 하였다.

어획능력을 측정하는 방법으로는 정성적 기 법에서 정량적 기법까지 다양하게 제안되고 있 다. 하지만 $\mathrm{FAO}$ 전문가그룹회의에서는 국제적 인 어획능력 측정을 위한 가장 효과적인 방법 중 의 하나로 '자료포락분석(Data envelopment analysis: DEA)' 기법을 제안하였다(FAO, 2000). 이는 $\mathrm{DEA}$ 기법이 활용 가능한 비교적 적은 자 료로 $\mathrm{FAO}$ 가 정의한 어획능력을 가장 효과적으 로 측정할 수 있기 때문이다. 이에 따라 지금까 지 대부분의 선행연구들도 DEA 기법을 활용하 여 어업별 어획능력을 측정해 오고 있다(Kirkley et al., 2003; Hsu, 2000; Pascoe and Coglan, 2000; Kirkley and Squires, 1999).

국제행동계획의 권고에 따라 우리나라에서도 어업별 어획능력 감축을 위한 국내행동계획을 수립하고자 하고 있다. 최근 우리나라 연근해 자 원량과 어획량 감소에도 불구하고 실질적인 어 획노력량 수준이 증가하고 있는 점을 감안할 때 어업자원의 회복을 통한 지속적이고 경영안정 적인 어업발전을 도모하기 위해서는 어업별 어 획능력을 정량적으로 측정하고, 과잉된 어획능 
력 감축을 위한 방안 마련이 시급한 실정이다. 이러한 배경 하에서 본 연구는 현재 우리나라 자 원회복계획 시범사업 대상어종인 낙지통발어업 을 대상으로 $\mathrm{FAO}$ 가 권고한 $\mathrm{DEA}$ 기법을 활용하 여 어획능력을 측정하였다. 또한 DEA 분석결과 에 대한 민감도 분석을 통해 현 어획량 수준 하 에서의 어획투입요소별 감축범위를 어선별로 추정하여 초과 어획능력 관리를 위한 정책적 시 사점을 제공하였다.

\section{재료 및 방법}

\section{DEA 기법}

$\mathrm{DEA}$ 기법은 선형계획법에 근거한 효율성 측 정방법으로서, 생산가능집합에서 적용되는 몇 가지의 기준 하에서 평가대상의 투입요소와 산 출물간의 자료를 이용해 경험적 효율성 프론티 어(생산활동의 상대적 기술효율성, technical efficiency)를 평가대상으로 비교하여 평가대상 의 효율치를 측정하는 비모수적 접근방법이다. $\mathrm{DEA}$ 의 기본원리는 모든 비교대상 의사결정단 위의 효율성은 1 보다 작거나 같다는 제약조건 하에서 평가하고자 하는 의사결정단위의 효율 성을 극대화하는 모형으로서 다음의 식 (1)과 같 이 나타낼 수 있다.

$$
\begin{aligned}
M A X & \sum_{m=1}^{M} z_{m} u_{j m} / \sum_{n=1}^{N} z_{n} x_{j n} \\
\text { s.j. } & \sum_{m=1}^{M} z_{m} u_{j m} / \sum_{n=1}^{N} z_{n} x_{j n} \leq 1 \\
& z_{m}, z_{n} \geq 0, j=1,2, \cdots, J
\end{aligned}
$$

여기서, $M$ 은 효율성을 측정하고자 하는 대상 의 사결정단위의 산출요소의 수이고, $N$ 은 투입요 소의 수를 나타내며, $u_{j m}$ 과 $x_{j n}$ 은 의사결정단위의 투입물과 산출물의 실제 관찰치를 나타낸다. 그 리고 $z_{m}$ 과 $z_{n}$ 은 대상 의사결정단위의 각 산출요 소와 투입요소의 가중치를 의미한다.

$\mathrm{DEA}$ 기법의 기본원리를 바탕으로 어획능력 측정을 위한 $\mathrm{DEA}$ 모형을 보다 구체적으로 살펴 보면, $\mathrm{DEA}$ 는 수리적 선형계획법을 이용하여 분
석대상 어선들의 어획노력 투입량과 최대[프론 티어(frontier)] 생산량과의 선형적인 관계식을 도출하게 된다. 즉, 주어진 투입요소량에 대한 최대 생산량을 산출하므로 이는 Johansen(1968) 의 정의와 $\mathrm{FAO}(2000)$ 가 제안한 바와 같이 어획 능력의 생산적인 개념과 완전히 일치하게 된다. $\ulcorner$ 어획노력 투입량-최대 어획량」관계식에 따 라 어선별 어획노력 투입량에 대한 최대 어획량 수준을 추정하고, 이를 실제 어획량과 비교함으 로써 어선별 어획능력 활용도(capacity utilization, $\mathrm{CU})$ 를 측정하게 된다. 그리고 이를 바탕으로 어 선별 어획능력의 초과 정도를 판단하고, 어선들 간의 어획능력 측정치를 비교함으로써 어선별 조업활동에 대한 기술적 효율성을 상대적으로 평가할 수 있게 된다.

예를 들어, Fig. 1은 어종 1과 2에 대한 투입 어 획노력당 어획량(CPUE)을 나타내고, 점 $\mathrm{A}, \mathrm{B}, \mathrm{C}$, $\mathrm{D}, \mathrm{E}$ 는 각 어선별 어종의 어획량 집합을 의미한 다. 투입 어획노력량 수준에 따른 각 어선별 최 대 어획량의 관계식을 DEA 기법으로 구하고, 투입 어획노력량 수준에 따른 각 어선별 최대 생 산량, 즉 최대 어획능력과 실제 어획능력을 구한 결과 어선 $\mathrm{A}, \mathrm{B}, \mathrm{C}, \mathrm{D}$ 는 실제 어획량이 최대 어획 량 수준과 일치하는 것으로 나타나 어획능력이 완전하게 이용되는 것으로 나타났다.

하지만 어선 $\mathrm{E}$ 의 경우 현재 어획노력 투입량 에 따른 최대 어획량 $\left(\mathrm{E}^{*}\right)$ 보다 실제 어획량 $(\mathrm{E})$ 이 적은 것으로 나타났다. 따라서 $\mathrm{DEA}$ 기법으로부

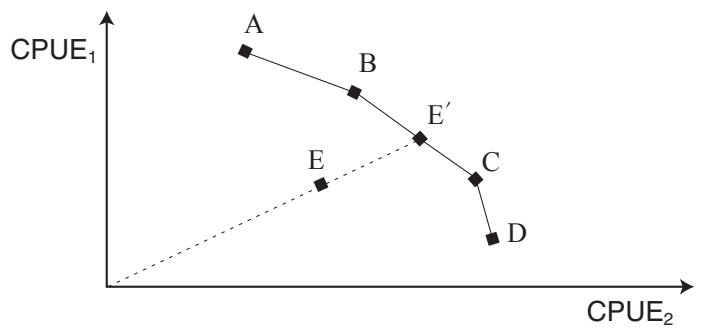

Fig. 1. Maximum(frontier) production curve. 
터 추정된 어획노력 투입량에 대한 최대 어획량 의 관계식에 따라 투입 어획노력량 수준을 조정 한다면 어종 1 과 2에 대한 어획량은 $\mathrm{E}$ 에서 $\mathrm{E}^{*}$ 로 증가할 수 있을 것이다. 여기서 $\mathrm{CU}$ 는 $\mathrm{OE} / \mathrm{OE}^{*}$ 가 되는데, 어선 $\mathrm{A}, \mathrm{B}, \mathrm{C}$, 그리고 $\mathrm{D}$ 의 경우 $\mathrm{CU}$ 는 1 이 된다.

Färe et al.(1989)는 실제 투입량에 따른 최대 생산능력 추정을 위한 DEA 모형을 식 (2)와 같 이 나타내었다.

$M A X \theta_{1}$

$$
\begin{array}{ll}
\text { s.j. } & \theta_{1} u_{j, m} \leq \sum_{j=1}^{J} z_{j} u_{j, m}, \quad \forall m \\
& \sum_{j=1}^{J} z_{j} x_{j, n} \leq x_{j, n}, \quad n \in F_{x} \\
& \sum_{j=1}^{J} z_{j} x_{j, n}=\lambda_{j, n} x_{j, n}, \quad n \in V \\
& z_{j} \geq 0, \quad \forall j \\
& \lambda_{j, n} \geq 0, \quad n \in V_{x}
\end{array}
$$

여기서, $\theta_{1}$ 은 개별 기업이 투입요소를 활용하여 얼마만큼 생산량을 증가시킬 수 있는지를 보여 주는 목적함수 값의 스칼라(scalar)이다. 따라서 실제 어획량에 $\theta_{1}$ 을 곱함으로써 최대 어획량 수 준을 도출할 수 있게 된다. $u_{j, m}$ 과 $x_{j, n}$ 은 앞의 식 (1) 에서와 같이 기업별 생산량 $(m)$ 과 투입요소(n), $F_{x}$ 와 $V$ 는 각각 고정 투입요소와 변동 투입요소를 나타낸다. 그리고 $z_{j}$ 는 투입요소들의 가중치, $\lambda_{j, n}$ 은 변동 투입요소의 투입활용도(input utilization rate)를 의미한다. 식 $(2-1)$ 은 기업별 생산품종별 생산량에 대한 제약조건식이고, 식 $(2-2)$ 는 고 정 투입요소에 대한 제약조건을 의미한다. 식 $(2-3)$ 은 변동 투입요소에 대한 조건으로, 변동 투입요소량은 DEA 모델에 의해 제약되지 않음 을 의미한다.

$\mathrm{DEA}$ 기법에서는 제약조건에 따른 목적함수 를 선형계획법으로 분석하는데, 분석 결과 기술 적 생산효율성(TE)을 극대화하는 $\theta_{1}$ 와 $z$ 의 값이 결정된다. 즉, 어획능력 측정을 위한 최대 어획 량은 어선별 실제 어획량에 $\theta_{1}$ 의 값을 곱하여 구 하고, 실제 어획량에 대한 어선별 어획능력 활용
도 $\left(C U_{o b s}\right)$ 는 다음의 식 (3)과 같이 구하게 된다.

$$
C U_{o b s}=\frac{u}{\theta_{1}^{*} u}=\frac{1}{\theta_{1}^{*}}
$$

$C U$ 값의 범위는 0 에서 1 까지로, $C U$ 값이 1 일 경 우 이는 어획능력이 완전(full) 활용되고 있음을, 하지만 $C U$ 값이 1 미만일 경우에는 유휴(초과) 어획능력이 존재하고 있음을 의미하게 된다.

그러나 식 (3)의 $C U_{o b s}$ 값은 하향 편향되었을 수도 있는데, 이는 식 $(2-3)$ 에서와 같이, 변동 투입요소량에 대한 제약이 없어 실제 어획량 수 준이 반드시 기술효율적(technically efficient)인 방법으로 생산되지 않았을 수도 있기 때문이다 (Färe et al., 1994). 따라서 기술효율적인 $C U$ 값 $\left(C U_{\text {eff }}\right)$ 추정을 위해서는 기술효율적인 생산량이 도출되어야 하는데, 이는 아래 식 (4)와 같은 변 동 투입요소에 대한 제약조건을 식 $(2-3)$ 에 대 체하여 목적함수 값 $(\theta)$ 을 구하면 된다.

$$
\sum_{j=1}^{J} z_{j} x_{j, n} \leq \lambda_{j, n} x_{j, n}, n \in V
$$

식 (4)를 식 $(2-3)$ 에 대체 하여 계산된 식 (2)의 목적함수 값을 $\theta_{2}$ 라고 하면, 기술효율적인 최대 어획량 수준은 어선별 실제 어획량에 $\theta_{2}$ 의 값을 곱하여 구하면 되고, 실제 어획량에 대한 어선별 기술효율적인 어획능력 활용도 $\left(C U_{e f f}\right)$ 는 다음의 식 (5)과 같이 계산된다.

$$
C U_{\text {eff }}=\frac{u}{\theta_{2}^{*} u}=\frac{1}{\theta_{2}^{*}}
$$

최종적으로 식 (3)과 (5)로부터 편향되지 않은 (unbiased) 어획능력 활용도(소위 'C $U_{F A R E}$ ')를 산출할 수 있는데, 이는 식 (6)에서 같이, $C U_{e f f}$ 에 대한 $C U_{o b s}$ 의 비율로써 구할 수 있다.

$$
C U_{F A R E}=\frac{\theta_{2}^{*} u}{\theta_{1}^{*} u}=\frac{\theta_{2}^{*}}{\theta_{1}^{*}}=\frac{C U_{o b s}}{C U_{\text {eff }}}
$$

즉, 식 (2)의 DEA 모형과 식 (4)를 대체한 DEA 모형을 수리적으로 해결함으로써 궁극적으로 3 가지 종류의 생산량 값(실제 어획량, 최대 어획 
량, 기술효율적 어획량)을 구할 수 있게 된다. 또 한 $C U_{e f f}$ 와 $C U_{o b s}$ 의 값으로부터 편향되지 않은 $C U$ 값을 도출함으로써 어선별 어획능력의 측정 과 비교가 가능하게 된다.

\section{분석 자료}

DEA 기법을 이용한 낙지통발어업의 어선별 어획능력 측정에 있어서는 2006년 4 6월(3개 월)간 고흥지역 실태조사에서 수집된 낙지통발 어업 어선별 일일 조업실적 자료를 사용하였다. Table 1에서 보는 바와 같이, 어선마다 생산량 및 각 투입요소별 차이가 다소 큰 것으로 나타났다. 예를 들어, 어획량의 경우 최소 $1,231 \mathrm{~kg}$ 에서 최 대 $3,945 \mathrm{~kg}$ 수준까지 차이가 있었으며, 톤수의 경우 1.87-7.31톤, 마력수 115-480마력, 조업 일수 34-64일, 그리고 출어당 어구사용량은 $501-1,227$ 개로 어선별로 큰 차이를 보였다.

DEA 분석에 있어서 생산량 자료로서는 낙지 통발어선이 거의 대부분 낙지만을 어획하고 위 판하기 때문에 낙지 어획량만을 사용하였다. 그 리고 투입요소 자료로서 우선 고정 투입요소로 는 어선별 마력수와 톤수 그리고 출어당 어구사 용량을 변수로 이용하였다. 이 외 변동 투입요소 로는 조업일수를 변수로 설정하여 이에 대한 어 선별 자료를 활용하였다.

Table 1. Vessel characteristics of octopus coastal trap fishery

\begin{tabular}{cccccr}
\hline Vessel & $\begin{array}{c}\text { Production } \\
(\mathrm{kg})\end{array}$ & Tonnage & $\begin{array}{c}\text { Horse } \\
\text { power }\end{array}$ & Days & $\begin{array}{c}\text { Traps } \\
\text { per trip }\end{array}$ \\
\hline 1 & 2,699 & 4.98 & 360 & 48 & 963 \\
2 & 1,722 & 6.67 & 480 & 34 & 815 \\
3 & 2,045 & 4.97 & 302 & 35 & 835 \\
4 & 2,741 & 4.70 & 370 & 50 & 1,003 \\
5 & 2,412 & 7.31 & 265 & 43 & 886 \\
6 & 1,231 & 5.74 & 281 & 37 & 501 \\
7 & 2,850 & 4.85 & 290 & 45 & 903 \\
8 & 3,229 & 1.87 & 115 & 54 & 1,227 \\
9 & 3,945 & 1.92 & 140 & 64 & 1,174 \\
10 & 3,590 & 5.10 & 302 & 63 & 1,090 \\
\hline Average & 2,646 & 4.81 & 291 & 47 & 940 \\
\hline
\end{tabular}

\section{결과 및 고찰}

식 (2)의 최대 어획량 모형에 대한 DEA 분석 결과, Fig. 2에서 보는 바와 같이, 어선별 실제 어 획 량(observed output)에 대한 최대 어획 량 (maximum output) 수준이 구해졌다. 어선 8 과 9 의 경우 실제 어획량과 최대 어획량이 거의 일치 하여 어획능력 활용도 $\left(C U_{o b s}\right)$ 가 $1(100 \%)$ 로 나타 났다. 하지만 다른 어선들의 최대 어획량은 실제 어획량 수준보다 높아 $C U_{o b s}$ 는 $1(100 \%)$ 미만으 로 평가되었다.

낙지통발어업 표본어선들의 평균 $C U_{o b s}$ 는 약 $85 \%$ 로 나타났는데, 이는 어선들에 있어 평균 $15 \%$ 정도의 유휴 어획능력이 존재하고 있다는 것을 의미한다. 특히 어선들 중 어선 2 의 $C U_{o b s}$ 가

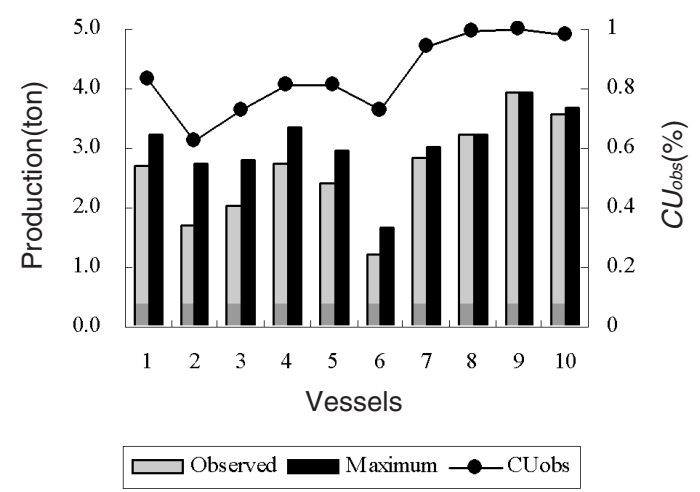

Fig. 2. Observed, maximum production, and $C U_{o b s}$ for individual vessels.

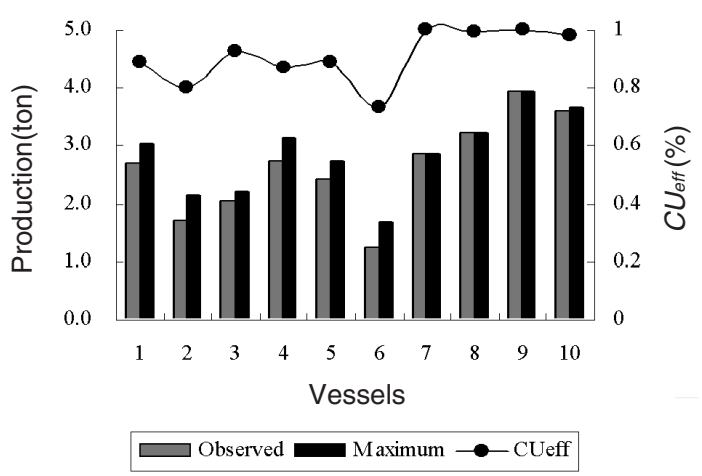

Fig. 3. Observed, maximum production, and $C U_{\text {eff }}$ for individual vessels. 
$63 \%$ 로 가장 낮게 측정되었다. 이는 실제 어획 량 $1,722 \mathrm{~kg}$ 을 어획하기 위해서는 현 어획능력의 $63 \%$ 수준으로도 어획할 수 있음을 의미하여 어 획능력 초과수준이 다른 어선에 비해 상대적으 로 높음을 시사한다.

식 (4)를 대체한 기술 효율적 어획량 모형에 대한 DEA 분석 결과에 있어서는 Fig. 3 에서 보 는 것과 같이, 어선별 실제 어획량에 대한 기술 효율적 어획량(technical efficient output)이 추정 되었다. 낙지 연안통발어업 어선들의 평균 $C U_{\text {eff }}$ 는 약 $91 \%$ 로 나타나, 평균 $C U_{o b s}$ 값보다 다소 높 게 측정되었다. 어선별에 있어서도 어선 7,8 , 그 리고 9의 $C U_{\text {eff }}$ 가 $1(100 \%)$ 로 나타난 반면, $C U_{o b s}$ 값이 가장 낮았던 어선 2 의 경우 $C U_{\text {eff }}$ 가 0.8 수준 으로, 초과 어획능력 수준이 다소 줄어든 것으로 평가되었다.

추정된 $C U_{e f f}$ 와 $C U_{o b s}$ 를 바탕으로 식 (6)을 이용 하여 최종적으로 편향되지 않은 낙지통발어업 어선별 $C U_{F A R E}$ 를 측정한 결 과는 다음의 Table 2에 서 보는 바와 같다. 어선별 평균 $C U_{F A R E}$ 는 0.93 으 로 $C U_{o b s}$ 와 $C U_{e f f}$ 에 비해 다소 높은 것으로 나타나 초과 어획능력 수준이 다소 줄어든 것으로 평가 되었다. 그리고 어선 $6,8,9$, 그리고 10 의 $C U_{F A R E}$ 가 $1(100 \%)$ 로 나타나 초과 어획능력이 존재하지 않는 것으로 측정되었다. 이에 반해 어선 2와 3 의 경우 모두 $C U_{F A R E}$ 가 0.79 로 가장 낮게 평가되었는 데, 이는 이들 어선의 초과 어획능력 수준이 약 $21 \%$ 로 어획량 증대 혹은 투입요소량 삭감을 통 한 어획능력 관리가 필요함을 시사해 준다.

다음으로 표본 어선 중 초과 어획능력 감축수 준을 보다 실증적으로 분석하기 위하여 DEA 결 과에 대한 민감도 분석을 추가적으로 실시해 보 았다. 구체적으로 민감도 분석에 있어서는 현재 투입노력량 수준에서의 감축수준을 분석하기 위해 기술 효율적 생산량을 추정한 DEA 분석 결과를 바탕으로 하였다.

민감도 분석 결과, Table 3에서 보는 바와 같 이, 현 어획량 수준 하에서 어선 1 의 경우 톤수
Table 2. $C U_{o b s}, C U_{e f f}$, and $C U_{F A R E}$ for individual vessels

\begin{tabular}{cccc}
\hline Vessel & $C U_{\text {obs }}$ & $C U_{\text {eff }}$ & $C U_{\text {FARE }}$ \\
\hline 1 & 0.83 & 0.89 & 0.94 \\
2 & 0.63 & 0.80 & 0.79 \\
3 & 0.73 & 0.92 & 0.79 \\
4 & 0.81 & 0.87 & 0.94 \\
5 & 0.81 & 0.89 & 0.91 \\
6 & 0.73 & 0.73 & 1.00 \\
7 & 0.94 & 1.00 & 0.94 \\
8 & 1.00 & 1.00 & 1.00 \\
9 & 1.00 & 1.00 & 1.00 \\
10 & 0.98 & 0.98 & 1.00 \\
\hline Average & 0.85 & 0.91 & 0.93 \\
\hline
\end{tabular}

Table 3. Results of sensitivity analysis on fishing capacity reduction levels for individual vessels

\begin{tabular}{cccccccc}
\hline \multirow{2}{*}{ Vessel } & \multicolumn{3}{c}{ Capacity reduction level } & & \multicolumn{2}{c}{$C U_{\text {eff }}$} \\
\cline { 2 - 3 } \cline { 7 - 8 } & Tonnage & HP & Days & $\begin{array}{c}\text { Traps } \\
\text { per trip }\end{array}$ & $\begin{array}{c}\text { Before } \\
\text { reduction }\end{array}$ & $\begin{array}{c}\text { After } \\
\text { reduction }\end{array}$ \\
\hline 1 & $-11 \%$ & $-26 \%$ & $-11 \%$ & $-11 \%$ & & $89 \%$ & $100 \%$ \\
2 & $-56 \%$ & $-63 \%$ & $-20 \%$ & $-33 \%$ & & $80 \%$ & $100 \%$ \\
3 & $-30 \%$ & $-31 \%$ & $-8 \%$ & $-22 \%$ & & $92 \%$ & $100 \%$ \\
4 & $-13 \%$ & $-33 \%$ & $-13 \%$ & $-14 \%$ & & $87 \%$ & $100 \%$ \\
5 & $-46 \%$ & $-11 \%$ & $-11 \%$ & $-14 \%$ & & $89 \%$ & $100 \%$ \\
6 & $-90 \%$ & $-84 \%$ & $-46 \%$ & $-27 \%$ & & $73 \%$ & $100 \%$ \\
8 & $-19 \%$ & $-3 \%$ & $-3 \%$ & $-22 \%$ & & $97 \%$ & $100 \%$ \\
10 & $-13 \%$ & $-10 \%$ & $-13 \%$ & $-2 \%$ & & $94 \%$ & $100 \%$ \\
\hline Average & $-35 \%$ & $-33 \%$ & $-16 \%$ & $-18 \%$ & & $90 \%$ & \\
\hline
\end{tabular}

Note: Vessel 7 and 9 are excluded since their values of $C U_{\text {eff }}$ are $1(100 \%)$.

$11 \%$, 마력수 $26 \%$, 그리고 조업일수 및 출어당 어구사용량이 각각 $11 \%$ 정도 감축되어야 유휴 어획능력이 소멸되는 것으로 추정되었다. 특히 $C U_{\text {eff }}$ 값이 가장 낮은 어선 6 의 경우 효율적 어업 생산을 위해서는 톤수 $90 \%$, 마력수 $84 \%$, 조업일 수 $46 \%$, 그리고 출어당 어구사용량이 $27 \%$ 정도 크게 감축될 수 있는 것으로 평가되었다. 이에 반해 $C U_{\text {eff }}$ 값이 상대적으로 높은 어선 8 의 경우 현 어획량 수준 하에서 초과 어획능력을 없애기 위해서는 톤수 $19 \%$, 마력수 $3 \%$, 조업일수 $3 \%$, 그리고 출어당 어구사용량이 약 $22 \%$ 정도 줄어 들어야 하는 것으로 측정되었다. 


\section{결 론}

$\mathrm{FAO}$ 가 권고한 $\mathrm{DEA}$ 기법을 활용하여 고흥지 역 낙지 연안통발어업의 어선별 어획능력을 측 정해 본 결과 어선 전체적으로는 평균 $10 \sim 15 \%$ 정도 어획능력이 초과된 것으로 분석되었다. 그 리고 개별 어선별로는 초과 어획능력의 범위가 최대 $37 \%$ 수준까지 다양한 것으로 평가되었다. 이에 따라 보다 지속적이고 경영안정적인 낙지 어업발전을 도모하기 위해서는 초과 어획능력 감축을 위한 정책적 노력이 필요한 것으로 나타 났다. 그리고 보다 실증적인 어선별 어획능력 감 축수준 결정을 위한 $\mathrm{DEA}$ 측정결과에 대한 민감 도 분석에 있어서는, 어선별 투입노력량 감축범 위에 차이는 있지만, 현 어획량 수준 하에서 초 과 어획능력을 감축시키고 기술효율적인 생산 을 위해서는 전체 평균적으로 톤수 $35 \%$, 마력수 $33 \%$, 조업일수 $16 \%$, 그리고 출어당 어구사용량 이 약 $18 \%$ 정도 감축될 수 있을 것으로 평가되 었다. 특히 어선별 민감도 분석에 있어서는 조업 일수에 대한 가중치 비중이 가장 높게 평가됨으 로써 조업일수 조정을 통한 어획능력 관리방안 마련이 가장 효과적일 것으로 나타났다.

이러한 어선별 어획능력 측정결과는 어선간 의 생산성 혹은 어획성능의 비교를 가능하게 할 뿐만 아니라 민감도 분석 등을 통해 개별어선의 생산성 향상을 위한 구체적인 방안이나 투입요 소들의 감축수준에 대한 정책적 근거자료를 제 공해 줄 수 있다. 또한 자원관리 정책적 측면에 서도 어업별 혹은 어선별 어획능력을 측정하고, 자원회복을 도모할 수 있는 목표 어획량에 맞추 어 어획투입노력량 수준을 결정하여 감축방안 을 강구해 간다면 보다 실효성 있는 어업자원 관 리를 도모할 수 있을 것으로 기대된다.

\section{사 사}

이 연구는 국립수산과학원(수산자원회복을 위한 어업별 어획성능 정량화 연구, RP - $2007-$ $\mathrm{FE}-005)$ 의 지원에 의해 수행되었습니다.

\section{참고문헌}

FAO, 2000. Report of the technical consultation on the measurement of fishing capacity. FAO Fisheries Report, 615, pp. 92.

FAO, 1999. International plan of action for reducing incidental catch of seabirds in longline fisheries. International Plan of Action for the conservation and management of sharks. International Plan of Action for the management of fishing capacity. FAO COFI/99/5.

Färe, R., S. Grosskopf and C.A. Lovell, 1994. Production frontiers. Cambridge University Press, New York, pp. $1-312$.

Färe, R., S. Grosskopf and E. Kokkelenberg, 1989. Measuring plant capacity utilization and technical change : a non-parametric approach. International Economic Review, 30, 655 - 666.

Hsu, T., 2000. Simple capacity indicators for peak to peak and data envelopment analyses of fishing capacity-preliminary assessment. AGR/FI/RD (2000)9, pp. 90.

Johansen, L., 1968. Production functions and the concept of capacity. Namur: Centre d' Etudes et de la Recherche Universitaire de Namur, pp. 64-82.

Kirkley, J., D. Squires, M. Alam, and H. Ishak, 2003. Excess capacity and asymmetric information in developing country fisheries : The Malaysia purse seine fishery. Amer. J. Agr. Econ., 85(3), 647 - 662.

Kirkley, J., R Fäare, S. Grosskopf, K. McConnell, D. Squires and I. Strand, 2001. Assessing capacity and capacity utilization in fisheries when data are limited. North American Journal of Fisheries Management, 21, $482-497$.

Kirkley, J. and D. Squires, 1999. Capacity and capacity utilization in fishery industry. FI:MFC/99 Background document 20, Technical consultation on the measurement of fishing capacity. Mexico, pp. $32-48$.

Morrison, C.J., 1985a. Primal and dual capacity utilization: An application to productivity measurement in the U.S. automobile industry. Journal of Business and 
Economic Statistics, 3, 312-324.

Morrison, C.J., 1985b. On the economic interpretation and measurement of optimal capacity utilization with anticipatory expectations. Review of Economic Studies, 52, $295-310$.

Nelson, R., 1989. On the measurement of capacity utilization. Journal of Industrial Economics, 37(3), $272-286$.

Pascoe S., D. Greboval, J. Kirkley and E. Lindebo, 2004. Measuring and appraising capacity in fisheries:
Framework, analytical tools and data aggregation. FAO Fisheries Circular, No. 994, pp. 75.

Pascoe, S. and L. Coglan, 2000. Implications of differences in technical efficiency of fishing boats for capacity measurement and reduction. Marine Policy, 24, $301-307$.

Zheng, Y. and Y. Zhou, 2005. Measures of the fishing capacity of Chinese marine fleets and discussion of the methods. Journal of Oceanography, 61, 623 630.

2007년 7월 18일 접수

2007년 9월 20일 수리 